\title{
Repeat radiation with bevacizumab and minocycline in bevacizumab-refractory high grade gliomas: a prospective phase 1 trial
}

\author{
Adam L. Cohen ${ }^{1,2}\left(\mathbb{D} \cdot\right.$ Christopher J. Anker $^{3} \cdot$ Brett Johnson $^{2} \cdot$ Lindsay M. Burt ${ }^{2,4} \cdot$ Dennis C. Shrieve ${ }^{2,4}$. \\ Karen Salzman ${ }^{2,5} \cdot$ Randy Jensen $^{2,6} \cdot$ Ken Boucher $^{1,7} \cdot$ Howard Colman ${ }^{2,6}$
}

Received: 8 April 2020 / Accepted: 30 May 2020 / Published online: 6 June 2020

(c) The Author(s) 2020

\begin{abstract}
Introduction There are no effective treatments for gliomas after progression on radiation, temozolomide, and bevacizumab. Microglia activation may be involved in radiation resistance and can be inhibited by the brain penetrating antibiotic minocycline. In this phase 1 trial, we examined the safety and effect on survival, symptom burden, and neurocognitive function of reirradiation, minocycline, and bevacizumab.

Methods The trial used a $3+3$ design for dose escalation followed by a ten person dose expansion. Patients received reirradiation with dosing based on radiation oncologist judgment, bevacizumab $10 \mathrm{mg} / \mathrm{kg}$ IV every two weeks, and oral minocycline twice a day. Symptom burden was measured using MDASI-BT. Neurocognitive function was measured using the COGSTATE battery.

Results The maximum tolerated dose of minocycline was $400 \mathrm{mg}$ twice a day with no unexpected toxicities. The PFS3 was $64.6 \%$, and median overall survival was 6.4 months. Symptom burden and neurocognitive function did not decline in the interval between treatment completion and tumor progression.

Conclusions Minocycline $400 \mathrm{mg}$ orally twice a day with bevacizumab and reirradiation is well tolerated by physician and patient reported outcomes in people with gliomas that progress on bevacizumab.
\end{abstract}

Keywords Glioma $\cdot$ Reirradiation $\cdot$ Minocycline $\cdot$ Bevacizumab

\section{Introduction}

Adam L. Cohen

Adam.cohen@hci.utah.edu

1 Division of Medical Oncology, University of Utah School of Medicine, Salt Lake City, UT, USA

2 Huntsman Cancer Institute, Salt Lake City, UT, USA

3 Division of Radiation Oncology, University of Vermont Larner College of Medicine, Burlington, VT, USA

4 Department of Radiation Oncology, University of Utah School of Medicine, Salt Lake City, UT, USA

5 Department of Radiology, University of Utah School of Medicine, Salt Lake City, UT, USA

6 Department of Neurosurgery, University of Utah School of Medicine, Salt Lake City, UT, USA

7 Department of Epidemiology, University of Utah School of Medicine, Salt Lake City, UT, USA
Gliomas are the most frequent brain tumor, accounting for approximately $12-15 \%$ of all brain tumors [1]. Standard treatments following maximal safe resection, depending on histology, include radiation, chemotherapies such as temozolomide, CCNU, or PCV, tumor treating fields, and bevacizumab [2-5]. Recurrent gliomas remain a clinical challenge, however. In particular, once high grade gliomas have progressed following radiation, chemotherapy, and bevacizumab, no treatments are known to prolong survival. Indeed, the 6-month progression-free survival (PFS6) in such situations is generally $<10 \%$ in published studies $[6,7]$.

Although historically repeat fractionated radiation for gliomas was considered prohibitively toxic, modern radiation techniques allow for repeat radiation in many cases [8-14]. Several studies have directly assessed fractionated reirradiation with concomitant bevacizumab and have demonstrated its safety [15-18]. Only two groups have published 
on reirradiation for high grade gliomas after progression on bevacizumab, showing a median survival of 5.4 months [19] and 4.8 months [20]. Moreover, no study has documented quality of life or cognition following repeat radiation in this population.

Studies have identified activation of nuclear factor kappa $\mathrm{B}(\mathrm{NF \kappa B})$ as a key signaling factor promoting the mesenchymal subtype and radiation resistance in glioblastoma (GBM) $[21,22]$. Activation of NFKB in glioma stem-cell cultures by tumor necrosis factor (TNF) treatment resulted in radiation resistance that can be reversed by blocking NFKB. To test the role of microglia and NFKB activation on treatment resistance in vivo, treatment with minocycline, an inhibitor of microglia activation, led to a reduction of tumor grade and down-regulation of mesenchymal markers in intracranial glioma stem cell xenograft models [22].

Minocycline is a tetracycline-derivative that is FDA approved as an antibiotic. It also has anti-inflammatory properties that are not shared by all members of the tetracycline family. Because of its known ability to cross the blood-brain barrier [23], minocycline has potential as an anti-glioma agent and as a radiation sensitizer for glioma. Minocycline inhibits matrix metalloproteinase expression by microglia, thus reducing glioma invasion and expansion [24]. Minocycline also induces glioma cell death via autophagy and apoptosis [25]. Animals treated with local administration of minocycline to tumor xenografts have improved survival [26].

The present study is a phase 1 trial of the addition of minocycline to fractionated reirradiation and bevacizumab for people with gliomas that have progressed following all standard treatments, including bevacizumab. The trial incorporated serial measurement of symptom burden and cognitive function.

\section{Materials and methods}

\section{Study design}

An open-label, single arm, Phase 1, dose-escalation and dose-expansion clinical trial was conducted with patients enrolled at a single institution. The trial included adults with radiologically proven recurrent, intracranial glioma who had been previously treated with radiation, temozolomide and bevacizumab. Progression must have been documented by Response Assessment in Neuro-Oncology (RANO) criteria [27], and patients must have been at least 6 months from prior radiation. Subjects were required to have adequate hematologic, hepatic, and renal function and a Karnofsky Performance Status (KPS) of at least 50. The protocol did not limit the size of the tumor as long as the radiation oncologist determined reirradiation was feasible. Exclusion criteria included contraindications to bevacizumab, including uncontrolled hypertension, intracranial hemorrhage, recent surgery, or non-healing wounds, and contraindications to minocycline, such as lupus or connective tissue disease. Patients were considered evaluable if they had a dose limiting toxicity (DLT) during the DLT window or if they completed at least 28 days of minocycline and two infusions of bevacizumab without a DLT. The DLT window included the radiation and 28 days afterward. During dose escalation, unevaluable patients were replaced.

\section{Interventions}

Bevacizumab was given at the standard, FDA-approved dose of $10 \mathrm{mg} / \mathrm{kg}$ IV every two weeks. Radiation was individualized based on the best judgment of the radiation oncologist. Most subjects received 3750 centigray (cGy) in 15 fractions or $4000 \mathrm{cGy}$ in 20 fractions. Details of radiation planning are given in Table 2 . The gross tumor volume (GTV) was defined mostly as the T1 enhancing tumor, but given the effects on MRI imaging of antiangiogenic agents the T2/FLAIR abnormality could be included in the GTV at the judgment of the treating radiation oncologist. The median clinical target volume (CTV) margin was $0.5 \mathrm{~cm}$ (Range $0-2 \mathrm{~cm}$ ). The size of the CTV and the decision of whether to include T2/FLAIR in the GTV were based on the judgment of the treating radiation oncologist taking into consideration MRI changes over time, prior radiation, and anatomic location. The median planning treatment volume (PTV) margin was $0.3 \mathrm{~cm}$ (Range 0-0.7 cm). The median PTV size was $192.3 \mathrm{~cm}^{3}$ (Range $0.3-487 \mathrm{~cm}^{3}$ ). The median RT dose was $3750 \mathrm{cGy}$ (Range 2000-5400 cGy) in 15 fractions (Range 5-30). Intensity modulated radiation therapy (IMRT) was used in all patients but one, who received stereotactic radiosurgery (SRS). Minocycline was taken orally twice a day starting on the day prior to radiation and continuing until progression or intolerance. Three dose levels of minocycline were tested: $100 \mathrm{mg}$ twice a day, $200 \mathrm{mg}$ twice a day, and $400 \mathrm{mg}$ twice a day.

\section{Safety assessments}

The primary endpoint was the rate of adverse events during and up to 28 days after radiation. All patients who received a dose of minocycline were included in the safety analysis. DLTs were defined as grade 3 or intolerable grade 2 toxicities (other than anemia, lymphopenia, high cholesterol, or weight gain) related to the minocycline occurring during or within 28 days of the end of radiation. 


\section{Efficacy and PRO assessments}

The secondary endpoints were progression-free survival (PFS) at three (PFS3) and 6 (PFS6) months from the beginning of study treatment, the overall response rate, and changes over time in symptom burden and cognitive function. PFS was defined from the date of start of minocycline until the day of documented disease progression or death. PFS was only assessed in patients on the maximal tolerated dose (MTD) of minocycline. Patients who declined followup or did not complete radiation were censored at the time of study withdrawal. Patient symptom burden and symptom interference were measured using the MDASI-BT [28]. Cognitive function was measured using COGSTATE brief battery (detection test (DET), identification test (IDN), one card learning test (OCLT), and Groton Maze Learning Test (GMLT)) [29] Symptom burden and cognitive function were measured at baseline, week 4, week 12, and week 26 before patients were seen by the neuro-oncologist or received any MRI results.

\section{Ethics}

The trial was approved by the University of Utah Institutional Review Board (IRB). It was registered on clinicaltrials.gov, NCT01580969, prior to beginning enrollment.

\section{Results}

\section{Demographics and clinical characteristics}

Twenty-three patients were screened between July, 2012 and November, 2017, of which twenty-two were eligible and enrolled on the trial. Clinical characteristics are summarized in Table 1. Six people enrolled at the $100 \mathrm{mg}$ twice a day dose level, three at the $200 \mathrm{mg}$ twice a day dose level and thirteen at the $400 \mathrm{mg}$ twice a day dose level. All patients have completed follow up and have died. Three people enrolled at the lowest dose did not complete radiation due to patient preference despite not having any DLT, so they were replaced (Table 2).

Most patients had GBM or multiply recurrent lower grade gliomas without approved systemic treatment options. All patients treated at the $400 \mathrm{mg}$ twice a day dose had either grade III or IV gliomas at initial diagnosis. Of the 22 patients, 13 had unknown IDH status, although one of these was a $1 \mathrm{p} / 19 \mathrm{q}$ codeleted anaplastic oligodendroglioma that was presumably IDH mutated and two were GBMs with EGFRvIII mutation that were presumably wild-type. Of the rest, 6 were IDH wild-type, including 4 GBMs, 1 grade IV glioneuronal tumor, and 1 grade II astrocytoma., and three were IDH mutated, including one GBM and two anaplastic
Table 1 Demographics of participants

\begin{tabular}{|c|c|c|c|}
\hline Characteristic & Number & & $\%$ \\
\hline \multicolumn{4}{|l|}{ Gender } \\
\hline Male & 14 & & 64 \\
\hline Female & 7 & & 32 \\
\hline Declined & 1 & & 5 \\
\hline \multicolumn{4}{|l|}{ Age } \\
\hline Median & & 55.5 & \\
\hline Range & & $31-76$ & \\
\hline \multicolumn{4}{|l|}{ Race } \\
\hline White & 20 & & 91 \\
\hline Declined & 2 & & 9 \\
\hline \multicolumn{4}{|l|}{ Ethnicity } \\
\hline Non-hispanic & 19 & & 86 \\
\hline Hispanic & 1 & & 5 \\
\hline Declined & 2 & & 9 \\
\hline \multicolumn{4}{|l|}{ KPS } \\
\hline 60 & 5 & & 23 \\
\hline 70 & 1 & & 5 \\
\hline 80 & 11 & & 50 \\
\hline 90 & 5 & & 23 \\
\hline \multicolumn{4}{|l|}{ Prior therapies } \\
\hline Median & & 3 & \\
\hline Range & & $2-6$ & \\
\hline \multicolumn{4}{|l|}{ Time from last surgery (months) } \\
\hline Median & & 41 & \\
\hline Range & & $2.3-153$ & \\
\hline \multicolumn{4}{|l|}{ Original histology } \\
\hline Anaplastic astrocytoma & 3 & & 14 \\
\hline Grade II astrocytoma & 2 & & 9 \\
\hline GBM & 13 & & 59 \\
\hline Grade II oligodendroglioma* & 1 & & 5 \\
\hline Anaplastic oligodendroglioma & 1 & & 5 \\
\hline Anaplastic oligoastrocytoma* & 1 & & 5 \\
\hline Grade IV glioneuronal tumor & 1 & & 5 \\
\hline
\end{tabular}

${ }^{*}$ The $1 \mathrm{p} / 19 \mathrm{q}$ was not codeleted, so by 2016 WHO criteria, these tumors would have been classified as astrocytomas

KEY: GBM glioblastoma, KPS karnofsky perfromance status

astrocytomas. The tumor that was called anaplastic oligodendroglioma histologically was $1 \mathrm{p} / 19 \mathrm{q}$ codeleted, but the tumor that was called grade II oligodendroglioma was not $1 \mathrm{p} / 19 \mathrm{q}$ codeleted so by current criteria would have been called an astrocytoma.

\section{Safety}

The maximum tolerated dose of minocycline in this population was $400 \mathrm{mg}$ twice a day. Of the patients who started at $400 \mathrm{mg}$ twice a day, nine (70\%) were able to complete radiation without stopping or reducing the minocycline. 


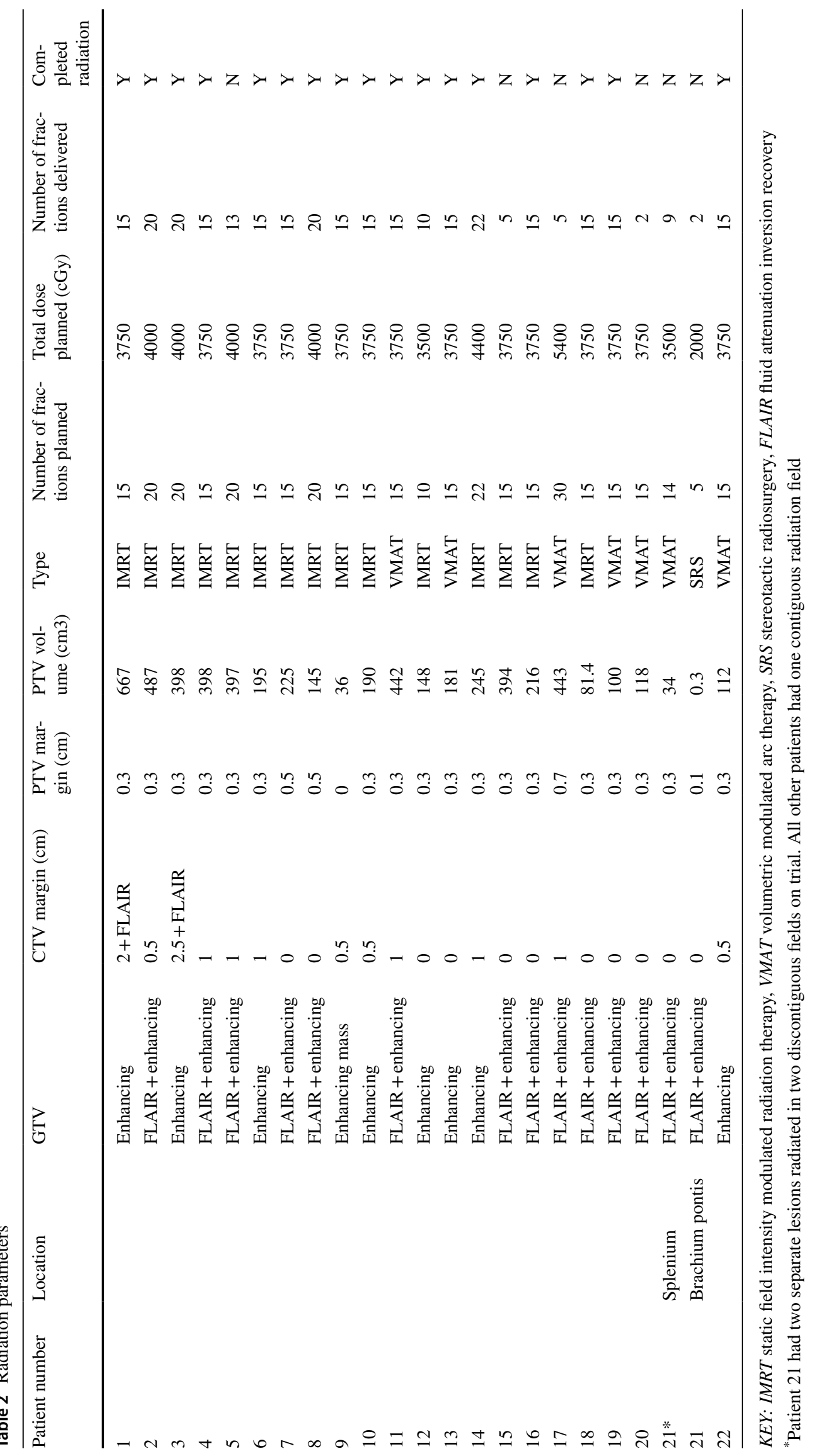


Adverse events were consistent with the known side effect profiles of minocycline, bevacizumab, and radiation. Grade 3 or higher adverse events and adverse events that occurred in more than one person are summarized in Table 3. Grade 3 or higher adverse events occurred in $24 \%$ of subjects and all resolved with supportive care or holding the minocycline. No patient had symptomatic radiation necrosis or radiation necrosis requiring treatment. There were no DLTs in the dose escalation and one DLT in the dose expansion (grade 3 nausea, dehydration, and confusion possibly related to the minocycline).

\section{Efficacy}

PFS and OS were assessed in all patients who started treatment at the $400 \mathrm{mg}$ twice a day dose. The PFS3 in this group was $64.6 \%$ (95\% confidence interval (CI) 42.8-99.8\%), and the PFS6 was $27.7 \%$ (95\% CI 10.6-72.3\%), which compares favorably with PFS3 and PFS6 seen in other trials of patients who progressed on bevacizumab. The median PFS was 3.8 months (95\% CI 2.5 months-infinity), and the median OS was 6.4 months (95\% CI 4.2 months-12.1 months). Radiographic responses were rare, with one person with a gemistocytic astrocytoma treated at the $100 \mathrm{mg}$ twice a day dose level having a complete response and one person with a GBM treated at the $200 \mathrm{mg}$ twice a day level having a partial response. For all 22 people who enrolled on the trial, the median PFS was 3.8 months (95\% CI 2.5-8.1 months). The PFS3 was $65.3 \%$ (95\% CI 47.5-89.8\%), and the PFS6 was $35.2 \%$, (95\% CI 19.4-63.8\%).

\section{Symptom burden and cognitive outcomes}

Compliance with the MDASI-BT was high with $100 \%$ compliance at baseline ( 22 out of 22 eligible patients), week 12 (nine out of nine eligible patients), and week 26 (four out

Table 3 Adverse events (AEs)

\begin{tabular}{|c|c|c|c|}
\hline Toxicity code & $\begin{array}{l}\text { Dose Level 0: } \\
100 \mathrm{mg}\end{array}$ & $\begin{array}{l}\text { Dose Level 1: } \\
200 \mathrm{mg}\end{array}$ & $\begin{array}{l}\text { Dose } \\
\text { Level 2: } \\
400 \mathrm{mg}\end{array}$ \\
\hline Total patients experiencing any G3-4 AE & $0 / 3$ & $1 / 3$ & $3 / 13$ \\
\hline Diarrhea & 0 & 0 & 1 \\
\hline Hypertension & 0 & 0 & 1 \\
\hline Hypokalemia & 0 & 1 & 0 \\
\hline Insomnia & 0 & 0 & 1 \\
\hline Nausea & 0 & 0 & 1 \\
\hline Thromboembolic event & 0 & 0 & 2 \\
\hline Urinary incontinence & 0 & 0 & 1 \\
\hline Total patients experiencing any $G 1-2 A E$ & $3 / 3$ & $3 / 3$ & $11 / 13$ \\
\hline Anorexia & 0 & 0 & 4 \\
\hline Ataxia & 0 & 0 & 2 \\
\hline Constipation & 0 & 0 & 3 \\
\hline Cough & 0 & 0 & 4 \\
\hline Dehydration & 0 & 0 & 2 \\
\hline Dermatitis radiation & 1 & 0 & 2 \\
\hline Diarrhea & 0 & 0 & 4 \\
\hline Dizziness & 1 & 1 & 6 \\
\hline Dysarthria & 0 & 0 & 2 \\
\hline Edema limbs & 0 & 0 & 2 \\
\hline Fatigue & 1 & 1 & 4 \\
\hline Gait disturbance & 1 & 0 & 2 \\
\hline Headache & 2 & 2 & 2 \\
\hline Hoarseness & 0 & 0 & 2 \\
\hline Hypertension & 1 & 2 & 1 \\
\hline Insomnia & 0 & 0 & 2 \\
\hline Memory impairment & 0 & 0 & 3 \\
\hline Muscle weakness & 0 & 0 & 3 \\
\hline Nausea & 0 & 1 & 5 \\
\hline Nervous system disorders-Other & 0 & 1 & 2 \\
\hline Vomiting & 0 & 1 & 3 \\
\hline
\end{tabular}


MDASI-BT subscales

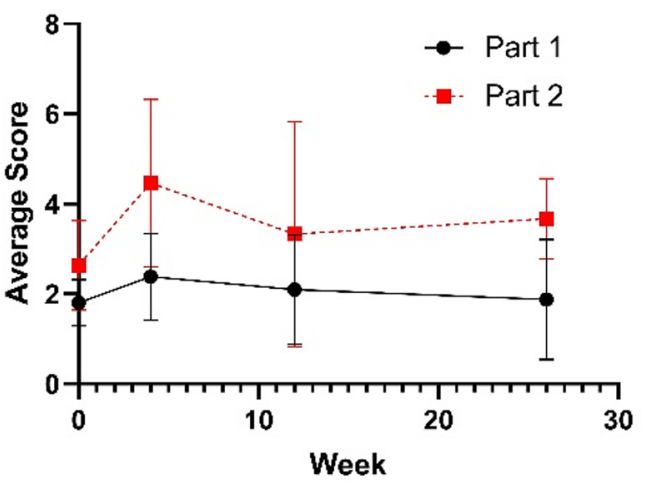

Interference with general activity

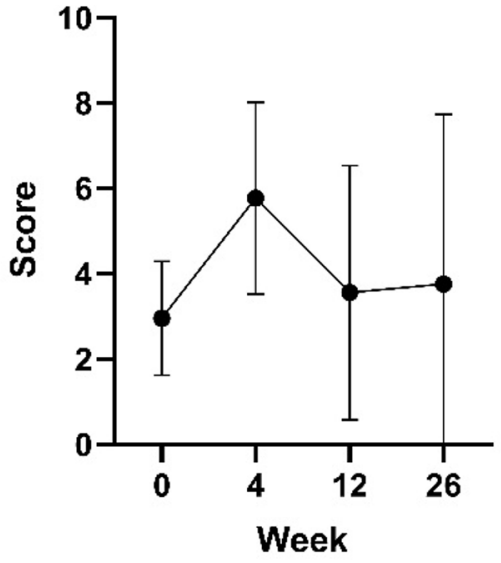

Interference with walking

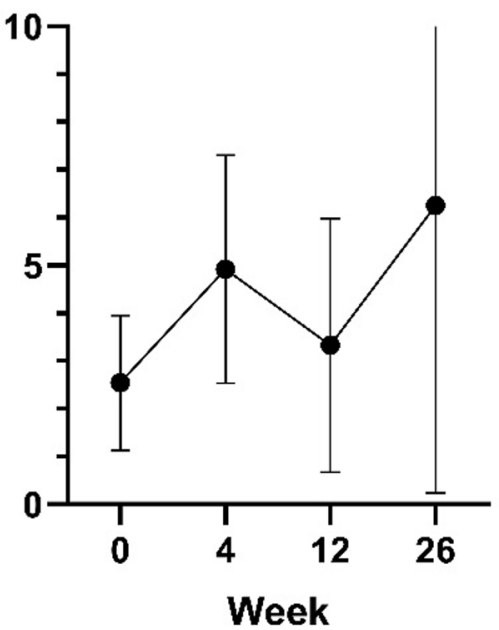

Fatigue

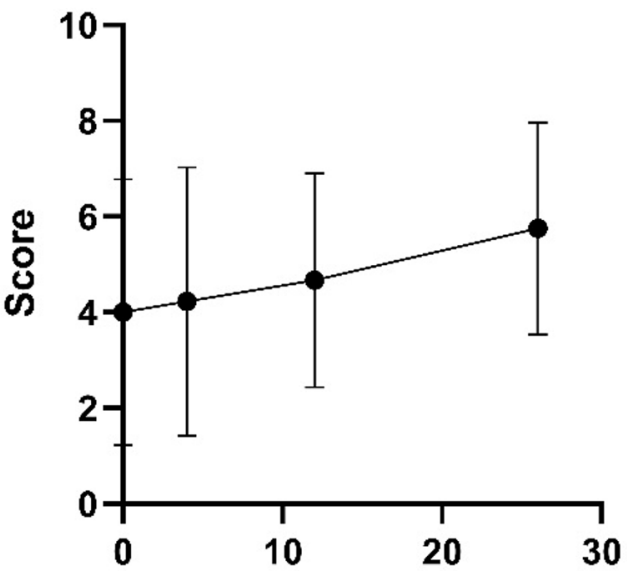

Interference with work

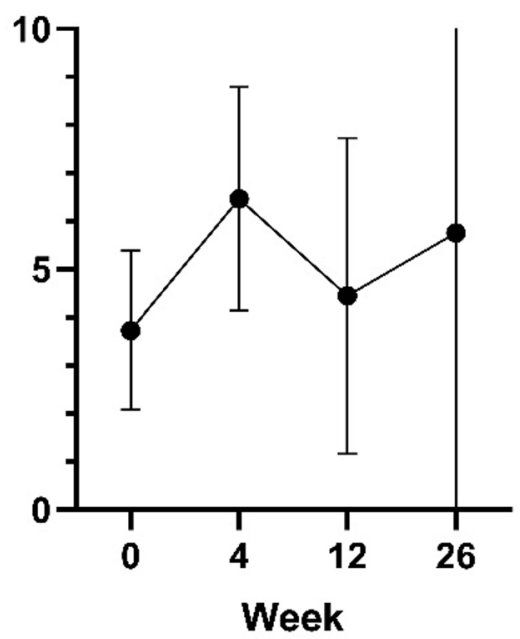

Interference with enjoyment

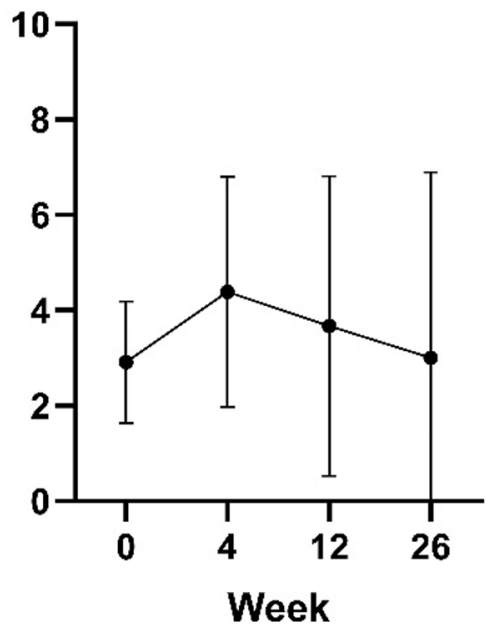


४Fig. 1 MDASI-BT results for symptom burden and symptom interference subscores (a) and for items with moderate or higher average scores (b-f). Mean and 95\% CI are presented for each time point

of four eligible patients) and 93\% compliance at week 4 (13 out of 14 eligible patients). At baseline, the average MDASIBT score was in the moderate range (4-6) for fatigue and memory problems. At week 4, the average MDAS-BT score was in the moderate range for fatigue and memory, and the average interference score was in the moderate range for general activity, walking and enjoyment of life, while the interference with work score had gone into the severe range $(>6)$. By week 12, however, the interference scores were all below moderate, except for interference with work, which was still in the moderate range. Average scores for the two subscales of the MDASI-BT and for fatigue, interference with general activity, interference with work, interference with walking, and interference with employment are shown in Fig. 1.

Compliance with cognitive testing was $73 \%$ at baseline, $69 \%$ at week $4,55 \%$ at week 12 , and $75 \%$ at week 26 . Missing test data was almost exclusively due to inability to complete the testing due to slow cognition or difficulty with attention. Thus, the cognitive function of the patients without data on cognitive testing is likely worse than those with testing. Summary scores are shown in Table 4. Of those that completed testing, no significant cognitive declines were seen from baseline, except for the IDN, which declined from an average of $2.79 \mathrm{~s}$ to $2.86 \mathrm{~s}(\mathrm{p}=0.02)$ from baseline to 4 weeks. The IDN test measures processing speed. In particular, the DET, which is a measurement of attention, OCLT, which is a measurement of working memory, and GMLT, which is a measurement of visual learning and memory, did not worsen for people who did not progress.

\section{Discussion}

Our trial demonstrates the safety of reirradiation with bevacizumab and minocycline at a starting dose of $400 \mathrm{mg}$ twice a day for recurrent GBM after progression on radiation, temozolomide, and bevacizumab. The trial accrued before the approval of tumor treating fields. It adds a prospective trial to the literature showing that reirradiation of high grade gliomas after bevacizumab failure can be performed with acceptable tolerability.

The only other published studies of reirradiation after progression on bevacizumab for patients with high grade glioma included retrospective analyses by Schernberg et al. $(n=13)$ [19] and Shi et al. $(n=30)$ [20] Although the median overall survival in those series (5.4 months and 4.8 months, respectively) was only slightly lower than ours (6.4 months), radiation doses were different and more radiation was performed stereotactically. In addition, the median PTV in our trial is about twice that in the Schernberg series and about eight times that in the Shi series. The retrospective nature of those series also could introduce selection bias. Thus, the survival in this prospective trial compares favorably to those series. Moreover, the one prospective trial of reirradiation in recurrent GBM for bevacizumab-naïve patients, Radiation Therapy Oncology Group (RTOG) 1205, failed to show an incremental benefit of radiation given via $35 \mathrm{~Gy}$ in 10 fractions when added to bevacizumab in this population [30].

Trials of systemic therapies in gliomas after progression on bevacizumab have been disappointing. For example, veribulin had a PFS 1 of $20 \%$ and nintedanib has a PFS 3 of $0 \%$, compared to the PFS3 of $65 \%$ in this trial [31, 32]. Tumor treating fields, which have gone on to FDA approval and a successful phase 3 trial in upfront treatment of GBM, gave a median OS of 6 months in patients with prior bevacizumab failure in a post-hoc subgroup analysis of the EF-11 trial [3]. Although cross-trial comparison has known pitfalls, the OS curve for tumor treating fields is similar to that seen with minocycline, bevacizumab, and radiation in our trial. Thus, prospective evaluation of the benefit of minocycline is warranted.

The symptom burden and cognitive data support the tolerability of this regimen. Patients and providers might fear that additional treatments, particularly reirradiation, may prolong life at the expense of quality of life anticipating significant declines in symptoms or cognition. In this trial, the overall symptom burden and cognitive function of survivors remained stable without clinically significant changes before tumor progression. The interference of symptoms with function and quality of life did increase immediately after radiation but then returned back toward baseline over time. No other trial of reirradiation has assessed quality of life, symptom burden, or neurocognitive function systematically.

The main limitation in this trial is the inability to separate out the effects of the radiation, bevacizumab, and the minocycline. In addition to the usual difficulties with cross trial comparisons of single-arm, single-center trials, there are few other studies of radiation in bevacizumab-refractory GBM with which to compare. Survival in a small, single-arm, single institution trial such as this may not generalize. The $\mathrm{OS}$ in this trial does not seem markedly longer than radiation alone or tumor treating fields, suggesting further breakthroughs are needed in this population. In addition, radiation parameters in this trial were somewhat heterogeneous, as the radiation prescription was based on the individualized judgment of the radiation oncologist. However, we think this variability increases the generalizability of our results to real world practice. Lastly, tissue from immediately prior to treatment was not available, so no correlative molecular studies were performed to identify either the molecular subtypes of the participants' tumors or predictors of response. 
Table 4 Cognitive testing results. COGSTATE results for the detection test (DET), identification test (IDN), one card learning test (OCLT), and Groton Maze Learning Test (GMLT)

\begin{tabular}{|c|c|c|c|}
\hline \multicolumn{4}{|c|}{ Cognitive function descriptive statistics } \\
\hline Question & n completed & Mean (Seconds) & SD \\
\hline \multicolumn{4}{|c|}{ Baseline cognitive function } \\
\hline DET & 14 & 2.63 & 0.16 \\
\hline IDN & 16 & 2.79 & 0.09 \\
\hline OCLT & 16 & 0.89 & 0.17 \\
\hline GMLT & 16 & 89.31 & 30.81 \\
\hline \multicolumn{4}{|c|}{4 Week cognitive function } \\
\hline DET & 9 & 2.67 & 0.15 \\
\hline IDN & 8 & 2.86 & 0.09 \\
\hline OCLT & 9 & 0.81 & 0.09 \\
\hline GMLT & 9 & 75.33 & 27.45 \\
\hline \multicolumn{4}{|c|}{12 Week cognitive function } \\
\hline DET & 5 & 2.65 & 0.14 \\
\hline IDN & 5 & 2.79 & 0.11 \\
\hline OCLT & 5 & 0.82 & 0.05 \\
\hline GMLT & 5 & 77.40 & 28.02 \\
\hline \multicolumn{4}{|c|}{26 Week cognitive function } \\
\hline DET & 3 & 2.79 & 0.11 \\
\hline IDN & 3 & 2.88 & 0.09 \\
\hline OCLT & 3 & 0.87 & 0.14 \\
\hline GMLT & 3 & 65.33 & 19.86 \\
\hline
\end{tabular}

This trial demonstrates the safety and tolerability of minocycline, reirradiation, and bevacizumab. A recently completed Phase I trial at the University of Utah is assessing the safety and efficacy of minocycline added to radiation and temozolomide in the upfront treatment of high grade gliomas. (NCT02272270). This upfront trial includes correlative tissue and radiomic studies not possible in the recurrent setting, which will help inform the optimal population for future randomized trials. Future studies comparing radiation and bevacizumab with and without minocycline are warranted.

\section{Conclusion}

Reirradiation with bevacizumab and minocycline is safe in bevacizumab-refractory high grade gliomas. Further studies with minocycline or other radiosensitizers are indicated.
Acknowledgements We acknowledge support of funds in conjunction with grant P30CA042014 awarded to Huntsman Cancer Institute that supported this trial.

\section{Compliance with Ethical Standards}

Conflicts of interest All other authors declare to no conflicts of interest.

Ethical approval All procedures performed in studies involving human participants were in accordance with the ethical standards of the institutional and/or national research committee and with the 1964 Helsinki declaration and its later amendments or comparable ethical standards. Informed consent was obtained from all individual participants included in the study. HC declares the following: Advisory Board/Consultant: Genentech, Roche, Merck, Best Doctors, Karyopharm Therapeutics, Private Health, Orbus, Bayer, Forma Therapeutics. Research Funding (Site PI/Institutional Contract): Newlink Genetics, Plexxikon, Kadmon, Orbus, Merck, DNATrix, Abbvie, Beigene, Forma Therapeutics, GCAR, Array BioPharma. ALC declares the following: Research Funding (Site PI/Institutional Contract): Abbvie, BMS, Novartis, Roche/Genentech, Merrimack, Eli Lilly, Cantex, Diffusion Pharmaceuticals, Daiichi Sankyo, H3 Biomedicine, AstraZeneca, Acrotech, Biometrix.

Open Access This article is licensed under a Creative Commons Attribution 4.0 International License, which permits use, sharing, adaptation, distribution and reproduction in any medium or format, as long as you give appropriate credit to the original author(s) and the source, provide a link to the Creative Commons licence, and indicate if changes were made. The images or other third party material in this article are included in the article's Creative Commons licence, unless indicated otherwise in a credit line to the material. If material is not included in the article's Creative Commons licence and your intended use is not permitted by statutory regulation or exceeds the permitted use, you will need to obtain permission directly from the copyright holder. To view a copy of this licence, visit http://creativecommons.org/licenses/by/4.0/.

\section{References}

1. Dolecek T, Propp J, Stroup N, Kruchko C (2012) CBTRUS statistical report: primary brain and central nervous system tumors diagnosed in the united states in 2005-2009. Neuro Oncol 15(suppl 5):v1-v49

2. Stupp R, Mason WP, van den Bent MJ et al (2005) Radiotherapy plus concomitant and adjuvant temozolomide for glioblastoma. N Engl J Med 352(10):987-996

3. Stupp R, Taillibert S, Kanner A et al (2017) Effect of tumortreating fields plus maintenance temozolomide vs maintenance temozolomide alone on survival in patients with glioblastoma: a randomized clinical trial. JAMA 318(23):2306-2316

4. Buckner JC, Shaw EG, Pugh SL et al (2016) Radiation plus procarbazine, CCNU, and vincristine in low-grade glioma. N Engl J Med 374(14):1344-1355

5. Stupp R, Wong ET, Kanner AA et al (2012) NovoTTF-100A versus physician's choice chemotherapy in recurrent glioblastoma: a randomised phase III trial of a novel treatment modality. Eur J Cancer 48(14):2192-2202

6. Reardon DA, Desjardins A, Peters K et al (2011) Phase II study of metronomic chemotherapy with bevacizumab for recurrent 
glioblastoma after progression on bevacizumab therapy. J Neurooncol 103(2):371-379

7. Reardon DA, Desjardins A, Peters KB et al (2011) Phase 2 study of carboplatin, irinotecan, and bevacizumab for recurrent glioblastoma after progression on bevacizumab therapy. Cancer 117(23):5351-5358

8. Combs SE, Thilmann C, Edler L, Debus J, Schulz-Ertner D (2005) Efficacy of fractionated stereotactic reirradiation in recurrent gliomas: long-term results in 172 patients treated in a single institution. J Clin Oncol 23(34):8863-8869

9. Fogh SE, Andrews DW, Glass J et al (2010) Hypofractionated stereotactic radiation therapy: an effective therapy for recurrent high-grade gliomas. J Clin Oncol 28(18):3048-3053

10. Kim HK, Thornton AF, Greenberg HS et al (1997) Results of re-irradiation of primary intracranial neoplasms with three-dimensional conformal therapy. Am J Clin Oncol 20(4):358-363

11. Vordermark D, Kolbl O, Ruprecht K et al (2005) Hypofractionated stereotactic re-irradiation: treatment option in recurrent malignant glioma. BMC Cancer 5:55

12. Straube C, Kessel KA, Zimmer C et al (2019) A second course of radiotherapy in patients with recurrent malignant gliomas: clinical data on re-irradiation, prognostic factors, and usefulness of digital biomarkers. Curr Treat Options Oncol 20(9):71

13. Navarria P, Minniti G, Clerici E et al. 2019. Re-irradiation for recurrent glioma: outcome evaluation, toxicity and prognostic factors assessment. A multicenter study of the Radiation Oncology Italian Association (AIRO). J Neurooncol, 142(1): 59-67.

14. Shen CJ, Kummerlowe MN, Redmond KJ et al (2018) Re-irradiation for malignant glioma: toward patient selection and defining treatment parameters for salvage. Adv Radiat Oncol 3(4):582-590

15. Niyazi M, Ganswindt U, Schwarz SB et al. 2010. Irradiation and bevacizumab in high-grade glioma retreatment settings. Int $\mathbf{J}$ Radiat Oncol Biol Phys.

16. Gutin PH, Iwamoto FM, Beal K et al (2009) Safety and efficacy of bevacizumab with hypofractionated stereotactic irradiation for recurrent malignant gliomas. Int J Radiat Oncol Biol Phys 75(1):156-163

17. Flieger M, Ganswindt U, Schwarz SB et al (2014) Re-irradiation and bevacizumab in recurrent high-grade glioma: an effective treatment option. J Neurooncol 117(2):337-345

18. Hundsberger T, Brugge D, Putora PM et al (2013) Re-irradiation with and without bevacizumab as salvage therapy for recurrent or progressive high-grade gliomas. J Neurooncol 112(1):133-139

19. Schernberg A, Dhermain F, Ammari S et al (2018) Reirradiation with concurrent bevacizumab for recurrent high-grade gliomas in adult patients. Cancer Radiother 22(1):9-16

20. Shi W, Blomain ES, Siglin J et al (2018) Salvage fractionated stereotactic re-irradiation (FSRT) for patients with recurrent high grade gliomas progressed after bevacizumab treatment. J Neurooncol 137(1):171-177
21. Bhat KP, Salazar KL, Balasubramaniyan V et al (2011) The transcriptional coactivator TAZ regulates mesenchymal differentiation in malignant glioma. Genes Dev 25(24):2594-2609

22. Vaillant BD, Bhat K, Sulman EP et al. 2012. The NFkB pathway as a key mediator of the glioblastoma mesenchymal subtype in glioblastoma stem cells and human tumors. J Clin Oncol, 30(suppl; abstr 2002).

23. Smith DL, Woodman B, Mahal A et al (2003) Minocycline and doxycycline are not beneficial in a model of Huntington's disease. Ann Neurol 54(2):186-196

24. Markovic DS, Vinnakota K, van Rooijen N et al (2011) Minocycline reduces glioma expansion and invasion by attenuating microglial MT1-MMP expression. Brain Behav Immun 25(4):624-628

25. Liu WT, Lin CH, Hsiao M, Gean PW (2011) Minocycline inhibits the growth of glioma by inducing autophagy. Autophagy $7(2): 166-175$

26. Weingart JD, Sipos EP, Brem H (1995) The role of minocycline in the treatment of intracranial 9L glioma. J Neurosurg 82(4):635-640

27. Wen PY, Macdonald DR, Reardon DA et al (2010) Updated response assessment criteria for high-grade gliomas: response assessment in neuro-oncology working group. J Clin Oncol 28(11):1963-1972

28. Armstrong TS, Mendoza T, Gning I et al. 2006. Validation of the M.D. anderson symptom inventory brain tumor module (MDASIBT). J Neurooncol, 80(1): 27-35.

29. Maruff P, Thomas E, Cysique L et al (2009) Validity of the CogState brief battery: relationship to standardized tests and sensitivity to cognitive impairment in mild traumatic brain injury, schizophrenia, and AIDS dementia complex. Arch Clin Neuropsychol 24(2):165-178

30. Tsien C, Pugh S, Dicker AP et al (2019) Randomized phase II trial of re-irradiation and concurrent bevacizumab versus bevacizumab alone as treatment for recurrent glioblastoma (NRG Oncology/ RTOG 1205): initial outcomes and rt plan quality report. Int J Radiat Oncol Biol Phys 105(1):S78

31. Norden AD, Schiff D, Ahluwalia MS et al (2015) Phase II trial of triple tyrosine kinase receptor inhibitor nintedanib in recurrent high-grade gliomas. J Neurooncol 121(2):297-302

32. Chamberlain MC, Grimm S, Phuphanich S et al (2014) A phase 2 trial of verubulin for recurrent glioblastoma: a prospective study by the brain tumor investigational consortium (BTIC). J Neurooncol 118(2):335-343

Publisher's Note Springer Nature remains neutral with regard to jurisdictional claims in published maps and institutional affiliations. 